\title{
Mind the Gap: The Key to Advancing the Science and Policy on Alcohol-Intoxicated Witnesses is to expand the Study Population and Bridge the Researcher-Practitioner Gap
}

\section{Abstract}

Alcohol-intoxicated witnesses to crimes are highly prevalent. Eyewitness testimony is crucial in criminal investigation, but there are still very few studies on how alcohol affects witnesses' memory. Most of the existing research consists of experimental studies on social drinkers carried out in laboratories. In addition, law enforcement personnel lack knowledge and policy guidelines on how to interview and handle this potentially vulnerable witness group. This emerging research field could improve by including a broader study population in the scientific studies and developing policy guidelines for the police. The key to doing so is to bridge the researcher-practitioner gap.

Keywords: Alcohol; Intoxicated; Eyewitnesses; Crimes; Study population; Researcher-practitioner gap; Advance science; Legal policy guidelines

Received: September 09, 2017; Accepted: September 25, 2017; Published: September 30, 2017

\section{Introduction}

Imagine an ordinary Saturday evening where people are crowded into bars and restaurants. Suddenly, there is a dispute and someone takes a knife, stabs another person in the stomach and quickly escapes the crime scene. There are many witnesses in the bar and a lot of them have been drinking. For example, one person has a breath alcohol concentration (BAC) of $0.08 \%$ while another has a BAC of $0.20 \%$. There is also an alcoholdependent person in the bar who has a BAC of $0.35 \%$. Then there is a person who is going to work tomorrow and who is sober. If the witnesses reports different things or even contradict each other, which witness should the police trust in order to direct the criminal investigation in the right way and hopefully arrest the perpetrator? Also, does the police officer's perception of who is the most credible witness affect how much weight they give each person's testimony and does this affect the direction of the investigation? Does the perceived credibility have any correlation with the actual accuracy of the witnesses' memory? These are some of the questions that the current research is trying to examine more closely. However, as will be elaborated on, future research has to include a broader category of witnesses as well as to increase the researcher-practitioner collaboration in order to move this field forward.

\section{Angelica V Hagsand ${ }^{1,2 *}$ \\ 1 Department of Psychology, University of Gothenburg, Gothenburg, Sweden \\ 2 Department of Psychology, Florida International University, Miami, USA}

*Corresponding author: Angelica Hagsand

झ angelica.hagsand@psy.gu.se

Department of Psychology, University of Gothenburg, Haraldsgatan 1, Box 500, S-405 30 Gothenburg, Sweden.

Tel: (+46) 0317861853

Citation: Hagsand AV (2017) Mind the Gap: The Key to Advancing the Science and Policy on Alcohol-Intoxicated Witnesses is to expand the Study Population and Bridge the Researcher-Practitioner Gap. J Drug Abuse Vol.3 No.3:18 
without having any reported health problems or alcohol-abuse disorders, i.e., "social drinkers." Social drinkers are usually common in alcohol-related contexts such as bars, restaurants, homes and parties, environments that simultaneously yield high levels of alcohol-related violence. According to the Swedish National Council for Crime Prevention, $50-70 \%$ of all violent crimes in Sweden are alcohol-related $[3,4]$. This means that the victim, the perpetrator and/or the eyewitnesses are under the influence of alcohol at the time of the crime. Given this, a considerable number of social drinkers are involved in crimes, either as bystanders, victims or perpetrators.

A law-enforcement survey and an archival study found that alcohol-intoxicated witnesses to crimes are highly prevalent $[5,6]$. The survey of US police officers showed that intoxicated eyewitnesses were most commonly encountered in violent crimes, such as fights, domestic disputes, assaults, thefts and disorderly conduct. Investigative interviews with intoxicated witnesses were conducted on average five times a week [5]. Further, it seems to be a common belief among practitioners within the legal system that intoxicated eyewitnesses are less credible than sober eyewitnesses [6-8]. Given the high prevalence of intoxicated witnesses, it may seem surprising that so little research has been conducted on this topic. However, a logical explanation for the relatively scarce research is that it requires a large number of ethical considerations and ethical approval before it is possible to administer alcohol doses to human research participants in a laboratory experiment. As we will discuss below, there is a need to conduct more quasiexperimental studies in the field (i.e., in bars and restaurants) to improve ecological validity and see the extent to which the laboratory findings translate to real-life.

Ethical boundaries restrict administered doses of alcohol in the laboratory to be low to moderate and only healthy nonalcohol dependent individuals are included in the experiments. For example, a recently published laboratory study [9] used low-to-moderate doses of alcohol with the aim of allowing the witnesses to reach a BAC of around $0.08 \%$. After reaching this intoxication level, the participants witnessed a filmed mockcrime in the laboratory followed by several recall tasks (in this study: questioning similar to a police interview). The method in the study by Hagsand et al. [9] is a good example of the most commonly used experimental procedure employed in laboratories in the UK, USA and Sweden with respect to this new emerging research topic. Similar methods were employed in other studies in the field [10-16]. The approximately 15 published studies on alcohol and witness memory have overall found no negative impact of alcohol on witnesses' memory. Most importantly, the few studies that found a negative effect of alcohol on witnesses' recall all resulted in small differences between intoxicated and sober participants - differences that barely are of any practical significance for law enforcement officers. The relatively low-tomoderate levels of intoxication in combination with the inclusion of healthy non-alcohol-dependent participants in laboratory studies are likely key contributors to the overall lack of negative effects of alcohol on witnesses' memory. Despite the overall lack of significant findings, research on how social drinkers remember events is of course of great value given the fact that much of the population are social drinkers. The current scientific status is that social drinkers with a low-to-moderate intoxication level (BAC below $0.10 \%$ ) at the time of the crime can be rather reliable witnesses and often remember as accurately as sober witnesses. Of course, in this context it is important to highlight that memory does not function like a recording device. In other words - both sober and intoxicated witnesses can misremember, which can lead the criminal investigation in the wrong direction [9].

Although research on social drinkers is of tremendous importance, it is also important to keep in mind that intoxicated witnesses constitute a wide group, including the whole spectrum of naïve drinkers, social drinkers, alcohol-abusers and alcoholdependent individuals. For example, it is estimated that almost $6 \%$ of the Swedish population has alcohol-dependence or alcohol-abuse problems [17]. The pattern is similar in the US were the National Institute on Alcohol Abuse and Alcoholism [18] reported that $6.2 \%$ of adults (over the age of 18 ) have an alcohol use disorder (AUD). Given the large population in the US, this means that over 15 million individuals in the US suffer from an AUD. Furthermore, US law enforcement officers estimated that almost $40 \%$ of the intoxicated witnesses they encounter have alcohol-abuse problems [5]. In other words, it is common for law enforcement officers to interact with persons having alcoholproblems. However, to the author's knowledge, there are no scientific studies specifically on how witnesses with alcoholabuse or dependence remember a crime or how they should be interviewed by police and other law enforcement personnel in order to obtain plentiful and accurate reports.

In general, addiction research has shown that alcohol-abuse can lead to a decline in cognitive performance, including memory tasks [19]. Severe alcohol-abuse can also lead to Korsakoff syndrome. This is a condition that leads to impaired learning, difficulties remembering recent events and gaps in long-term memory [20]. Persons suffering from Korsakoff syndrome might also confabulate in order to explain events that they do not recall. This means that they will make up things that have not happened while they are unaware of the fact that these 'memories' only are confabulations [21]. Hence, the length and extent of alcohol consumption as well as the tolerance for alcohol are all factors that could affect both objective measures (i.e., number of recalled details and accuracy of details) and subjective measures (i.e., perceived credibility by law enforcement officers) in the eyewitness context.

To complicate the matter, it might also be that the witness has taken other drugs, which can affect their memory of the crime. Evans et al. [5] reported that law enforcement officers estimated that the largest groups of intoxicated witnesses were only under the influence of alcohol. The second largest group was witnesses under the influence of multiple substances and the third group was estimated to be under the influence of only one illegal drug (e.g. marijuana). This pattern corresponds well to research showing that alcohol is the most commonly used drug in society [2]. However, research has also shown an extensive use of marijuana in society over several decades $[22,23]$. Neuroscience 
has shown that marijuana can distort cognitive functioning such as working memory and episodic memory [24]. All those factors can affect the encoding of a crime and the later recall. So far, only one scientific study exists on how acute marijuana use affects witness memory [25]. Hence, more research is needed both on how marijuana affects witness memory, as well as how multiple substances affect witnesses' recall of a crime. In conclusion, it is not just one category of individuals that constitute the group of intoxicated witnesses. This must be reflected in scientific studies as well as in legal policy guidelines. Given the sensitive nature of this drug research and the potential harmful impact on research participants, it is paramount to conduct studies with high ethical standards in order to minimize harm to humans.

There are obviously both benefits and limitations of different methodological approaches (e.g. archival studies, laboratory experiments, quasi-experiments, field studies) when studying witness memory. The different approaches complement each other and help researchers to view the problem from different angles, which renders a more holistic knowledge base [26]. Given the importance of witness memory for the resolution of real-world crimes, researchers are encouraged to use different methodological approaches to study how alcohol and other drugs affect witness memory. In order to move towards a better scientific understanding of how alcohol affects eyewitnesses' memory as well as how to implement new policy guidelines in the legal context, a better collaboration between researchers and practitioners will be needed. For the research to advance, there is a crucial need to conduct more quasi-experiments in the field (i.e., in real bars), as well as pure field studies (i.e., to measure the intoxication level among rape victims at hospitals and analyze their testimonies given to the police and then try to match this with potential evidence from the crime scene). This would allow researchers to study the effect of higher intoxication levels on witness memory for real events that are not possible to study ethically in the laboratory. Also, in order to expand the study population beyond social drinkers, it is important to be creative and conduct studies that are ethically approved and designed in order to minimize the harm to the participants. One way of expanding the research to include alcohol-dependent individuals could be to invite sober individuals who are at a treatment center for alcohol-abuse problems to be part of a study. The research team could show a mock-crime video to the participants who are under treatment and then interview them afterwards in order to test their memory of the event. Although this ethical study setup does not allow researchers to test how an intoxicated alcoholdependent person remembers a real crime, it is still possible to examine how long-term alcohol abuse affects event memory. In order to expand the research, scientists need to develop better collaborations with practitioners in different areas (e.g. bar and restaurant owners, hospital staff, clinical psychologist, police officers and other law enforcement personnel).

Beyond this, it is important for scientists to educate law enforcement personnel on what the research currently shows when it comes to how low-to-moderate levels of alcohol affect witness memory. Given the current research findings, witnesses with low-to-moderate intoxication levels at the event are often as reliable as sober witnesses [9], which mean that they also could be perceived as a credible source of information in the investigation. In order to have an objective measure of the witnesses' intoxication levels, recommendations have been made in the past that police officers should try to measure witnesses' intoxication levels with a portable breathalyzer at the scene of the crime [27]. It is unclear if this is being conducted today, but $71 \%$ of US law enforcement officers reported several years ago that they do not measure the witnesses' intoxication level in an objective manner [5]. Similar, as noted by Palmer et al. [6], police officers in the US usually determined that a witness had consumed alcohol or another drug because the witness reported this (in $88 \%$ of the cases). Few officers took a breathalyzer test (9\%), or observed the witness engaging in alcohol or other drug intake (3\%). It could be the case that when the police arrive at the scene of the crime they primarily are focused on measuring the intoxication level of a victim or a potential suspect, instead of the witnesses' intoxication level. However, as recommended by Hagsand [27], it would be beneficial to also measure the witnesses' intoxication level. If this is not possible, then one solution is obviously to ask the witnesses about the amount of consumed alcohol prior to the crime. Expert witnesses are sometimes asked to retroactively estimate the intoxication level an individual might have reached after a certain drinking event. There are formulas (e.g. the revised Widmark formula) which can be used in order to calculate the approximate BAC an individual had at the time of consumption [28]. However, it is a well-established fact that many factors (e.g. gender, weight, tolerance to the drug, rate of alcohol absorption, genetics, mental and physical health) are involved in the relationship between a consumed amount of alcohol and the actual BAC level. Hence, two witnesses consuming the same amount of alcohol could reach different intoxication levels $[29,30]$. Also, self-reports where individuals estimate how many glasses of alcohol they have consumed can be false given that it can be difficult to remember [31]. Therefore, it is more beneficial to objectively measure the intoxication level of a witness through a breathalyzer immediately if possible, rather than to reconstruct an approximate intoxication level using formulas. Although scientists may have an important role in educating legal practitioners, it is equally important for scientists to listen well to the knowledge and needs of practitioners in order for a real collaboration to take place. Scientists should be cautious in taking the role of the educated scholar high up in the ivory tower, thinking that practitioners have all the time and economical resources needed in their everyday police practice or court work to be able to implement what research has found to be best practice.

\section{Conclusion}

Finally, if there is miscommunication between researchers and practitioners, no one will benefit. Neither the researchers nor the practitioners, nor, most importantly the witnesses, the victims, the innocent suspects and the potential new victims. In order to have efficient criminal investigations and a high level of legal security in the society, researchers and practitioners needs to expand their collaboration and understanding in this new crossdisciplinary field of legal psychology and addiction research. 


\section{References}

1 The Swedish National Committee for Psychological Sciences (2017) Rättspsykologi.

2 Nutt DJ, King LA, Phillips LD (2010) Drug harms in the UK: A multicriteria decision analysis. Lancet 376: 1558-1565.

3 Eksten A (2007) Misshandel mellan obekanta - kan fler brott klaras upp? Violence between strangers - can more crimes be resolved? (Report No. 2007:12). National Council for Crime Prevention, Stockholm, Sweden.

4 Ekström E (2009) Misshandel mellan obekanta - kan fler brott klaras upp? [Violence between strangers - can more crimes be resolved?] (Report No. 2009:16). National Council for Crime Prevention, Stockholm, Sweden.

5 Evans JR, Schreiber Compo N, Russano MB (2009) Intoxicated witnesses and suspects: Procedures and prevalence according to law enforcement. Psychol Public Pol Law 15: 194-221.

6 Palmer FT, Flowe HD, Takarangi MKT, Humphries JE (2013) Intoxicated witnesses and suspects: An archival analysis of their involvement in criminal case processing. Law Hum Behav 37: 54-59.

7 Evans JR, Schreiber Compo N (2010) Mock jurors' perceptions of identifications made by intoxicated eyewitnesses. Psychol Crime Law 16: 191-210.

8 Kassin SM, Tubb AV, Hosch H, Memon A (2001) On the "general acceptance" of eyewitness testimony research: A new survey of the experts. Am Psychol 56: 405-416.

9 Hagsand AV, Roos af Hjelmsäter E, Granhag PA, Fahlke C, Söderpalm Gordh A (2017) Witnesses stumbling down memory lane: The effects of alcohol intoxication, retention interval and repeated interviewing. Memory 25: 531-543.

10 Crossland D, Kneller W, Wilcock R (2016) Intoxicated witnesses: Testing the validity of the alcohol myopia theory. Appl Cogn Psychol.

11 Hagsand A, Roos af Hjelmsäter E, Granhag PA, Fahlke C, Söderpalm Gordh A (2013) Bottled memories. On how alcohol affects eyewitness' recall. Scand J Psychol 54: 188-195.

12 Hagsand A, Roos af Hjelmsäter E, Granhag PA, Fahlke C, Söderpalm Gordh A (2013) Do sober eyewitnesses outperform alcohol intoxicated eyewitnesses in a lineup? The European Journal of Psychology Applied to Legal Context 5: 23-47.

13 Schreiber Compo N, Evans JR, Carol RN, Kemp D, Villalba D, et al. (2011) Alcohol intoxication and memory for events: A snapshot of alcohol myopia in a real-world drinking scenario. Memory 19: 202210.

14 Schreiber Compo N, Evans JR, Carol RN, Kemp D, Villalba D, et al. (2012) Intoxicated eyewitnesses: Better than their reputation? Law Hum Behav 36: 77-86.
15 Schreiber Compo N, Carol RN, Evans JR, Pimentel P, Holness H, et al. (2017) Witness memory and alcohol: The effects of state-dependent recall. Law Hum Behav 41: 202-215.

16 Yuille JC, Tollestrup PA (1990) Some effects of alcohol on eyewitness memory. J Appl Psychol 75: 268-273.

17 Ramstedt M (2014) ANDT-bruket och dess negativa konsekvenser i den svenska befolkningen 2013 - en studie med fokus på missbruk och beroende samt problem för andra än brukaren relaterat till alkohol, narkotika, dopning och tobak. Rapport 55 STAD, Stockholm.

18 National Institute on Alcohol Abuse and Alcoholism (2017) Alcohol facts and statistics.

19 Perry C (2016) Cognitive decline and recovery in alcohol abuse. J Mol Neurosci 60: 383-389.

20 El Haj M, Kessels PCR, Matton C, Bacquet JE, Urso L, et al. (2016) Destination memory in Korsakoff's syndrome. Alcoholism: Clinical and Experimental Research 40: 1321-1327.

21 Kessels RPC, Kortrijk HE, Wester AJ, Nys GMS (2008) Confabulation behavior and false memories in Korsakoff's syndrome: Role of source memory and executive functioning. Psychiatry Clin Neurosci 62: 220-225.

22 Compton WM, Grant BF, Colliver JD, Glantz MD, Stinson FS (2004) Prevalence of marijuana use disorders in the United States. JAMA 291: 2114-2121.

23 Rahim-Juwel R, Carliner H, Shmulewitz D, Sarvet AL, Wall M, et al. (2017) Are gender differences in the prevalence of past-year marijuana use and risk perception in the U.S. narrowing from 2002 to 2013? Drug Alcohol Depend 171: 172.

24 Ilan $A B$, Smith ME, Gevins A (2004) Effects of marijuana on neurophysiological signals of working and episodic memory. Psychopharmacology 176: 214-222.

25 Yuille JC, Tollestrup PA, Marxsen D, Porter S, Herve HFM (1998) An exploration on the effects of marijuana on eyewitness memory. Int J Law Psychiatry 21: 117-128.

26 Memon A, Mastroberadrino S, Fraser J (2008) Münsterberg's legacy: What does eyewitness research tell us about the reliability of eyewitness testimony? Appl Cogn Psychol 22: 841-851.

27 Hagsand A (2014) Alcohol intoxicated eyewitnesses' memory. Department of Psychology, University of Gothenburg, Sweden.

28 Posey D, Mozayani A (2007) The estimation of blood alcohol concentration: Widmark revisited. Forensic Sci Med Pathol 3: 33-39.

29 Lee H, Roh S, Kim DJ (2009) Alcohol-induced blackout. Int J Environ Res Public Health 6: 2783-2792.

30 Paton A (2005) Alcohol in the body. BMJ 330: 85-87.

31 Barnett NP, Wei J, Czachowski C (2009) Measured alcohol content in college party mixed drinks. Psychol Addict Behav 23: 152-156. 